\section{Military Technical College Kobry El-Kobbah, Cairo, Egypt}

\section{$9^{\text {th }}$ International Conference on Civil and Architecture \\ Engineering \\ ICCAE-9-2012}

\title{
REDUCTION OF ADDITIONAL STRESS IN A BARRAGE DUE TO BLAST LOAD BY USING OPEN TRENCH
}

\begin{abstract}
Yasser El-Hakem*

Some structures are exposed to blast load due to different reasons such as; quarry blasting, explosions used in the construction of new roads, bomb, terrorist attack, or other artificial explosions. Ground vibrations are part of the output of the blasting operations. When their levels are high, they can cause damage to nearby structures. For example; cement companies has been in operation long time ago in some areas in Egypt using quarry blasting. Since then, new structures and new communities were established in these areas and some nearby structures were damaged due to ground vibrations (such as; some buildings in the $15^{\text {th }}$ of May city).

The reduction of the additional stress in the structures is necessary for the safety of the existing structures near the blast because even a small amount of blast can produce a serious damage to the structures. Most design codes have specified for the seismic vulnerability and also against vehicular collisions but there are no definite structural design criteria for the struc tures exposed to typical blast loadings.

This research is intended to investigate the effect of blast load on a water structure (barrage) when using open trench as low-cost barrier to reduce the internal forces induced in the structure during the blast. The barrage structure was chosen in this research because this type of water structures is of special importance in Egypt since they control the water management process.

The analysis of these structures should be carried out for different loading condition s. They are normally designed for dead load, live load and other occasional loads. To investigate the effect of blast load on the structure (with and without using trench), Finite element analysis model under dynamic load (blast load) has been established for the structure. Non-linear dynamic time history analysis was performed for the structure without using trench.

Then, an open trench was used as a wave barrier to reduce the effect of the ground vibrations induced by the blast on the internal forces of the structure. A parametric study was carried out to investigate the effect of different factors affecting the internal forces induced in the structural elements due to blast load such as; depth, width, and location of the trench. These factors are import ant for the safety of structures near the blast.
\end{abstract}

Keywords:

Blast, Explosion, Open trench, Dynamic load, and barrage

\footnotetext{
*Associate Professor, Construction Research Institute, National Water Research Center, Egypt
} 


\section{INTRODUCTION}

Some structures are exposed to blast load due quarry blasting, construction of new roads, bomb, terrorist attack, or other artificial explosions. The blast loads are considered as most extremes loads and even a small amount of blast can produce a serious damage to the structures. The blast waves produced on explosion travel even faster than the speed of sound. Blast pressure can create loads on structure that are many times greater than the normal design loads .

Wave barriers are used to reduce ground-borne vibrations induced by machine foundations and high speed trains. Most of these vibrations propagate in the soil in the form of surface waves and can travel for long distances. The dynamic transmitting behavior of soil can be modified by constructing a suitable wave barrier in the path of the propagating waves between the dynamic load and the affected structures to be protected. There is a wide range of construction types of wave barriers, varying from very stiff concrete walls or row of piles to very flexible gas mattresses or wave impeding barriers, where the latter is based on the cut-off frequency of a soil layer over rigid bedrock. This research investigates the efficiency of using open trench as a low cost barrier on reducing the internal forced induced in barrage due to blas toad.

The security and financial aspects of blasting restricts the experimental work, therefore many researches in the area of blast loading were performed using the numerical modeling technique. Huabei [1] developed three-dimensional Finite Element model to investigate the dynamic response and damage of a tunnel under internal blast loading. Kumar et al. [2] studied the dynamic response of structures semi-buried in soil subjected to near-field, non-contact blast loading due to explosion by using finite element analysis. They modeled the structure using shell elements, wherein, the effect of soil-structure interaction is considered by using Wolf's spring dashpot-mass elements. Nagy et al. [3] developed nonlinear numerical modelling to study the effects of surface explosions on buried reinforced concrete tunnel. Alzawi et al. [4] performed a full scale experimental study on vibration scattering using open and in-filled wave barriers filled with Geo-Foam materials.

\section{BLAST WAVE PROFILE}

The blast waves are produced whenever an explosion takes place. These waves propagate in the form of spherical waves resulting discontinuities in the structures. During this wave propagation, high pressure is generated. This entire process of the wave generation and propagation lasts for a few milliseconds. The initial step in blast analysis is the determination of the blast loads.

\subsection{Dynamic Loads}

The pressure of blast wave front increases instantaneously from ambient air pressure to peak static overpressure and then it decreases exponentially with time. This phase is known as positive phase. The over-static pressure decay depends upon properties of propagating medium, such as; density, speed of sound and ambient air pressure. The 
pressure of over expanded gases during cooling falls below atmospheric pressure. Therefore, the positive phase of the blast wave front is always followed by negative phase of very small intensity of large time duration. The positive phase is more relevant in studies of blast wave effects on structures because of its high amplitude of the overpressure and the concentrated impulse. The negative phase of the blast wave, therefore, is generally ignored. Figure 1 shows the exponential blast wave profile and the linearly decaying pressure-time history. The pressure-time history of an ideal air blast wave is given by Friedlander's equation [2] as;

$$
P(t)=P_{50}\left(1-\frac{t}{t_{0^{*}}}\right) \exp \left(\frac{b\left(t-t_{a}\right)}{t_{0^{*}}}\right)
$$

where, $P_{\text {so }}$ is the peak incident pressure, $t$ is the instantaneous time, $t_{0+}$ is the positive duration of the pressure pulse, $t_{\mathrm{a}}$ is the arrival time, and $b$ is decay coefficient depending upon the peak overpressure $p_{\mathrm{s}}$ of the shock wave. The scaled distance is given by $Z$ as;

$$
Z=\frac{R}{W^{1 / 3}}
$$

where, $R$ is the standoff distance from the explosion in meters and $W$ is the Trinitrotoluene (TNT) equivalent of the explosive charge weight in kilograms. Equation (1) is often simplified by a linearly decaying pressure -time history as follows:

$$
\begin{gathered}
P(t)=p_{s}\left[1-\frac{t}{T_{s}}\right] \\
\frac{p_{s}}{p_{0}}=\frac{808\left[1+(Z / 4.5)^{2}\right]}{\sqrt{1+(Z / 0.048)^{2}} \sqrt{1+(Z / 0.32)^{2} \sqrt{1+(Z / 1.32)^{2}}}} \\
\frac{T_{s}}{W^{1 / 3}}=\frac{980\left[1+(Z / 0.54)^{10}\right]}{\left[1+(Z / 0.02)^{3}\left[1+(Z / 0.74)^{6}\right] \sqrt{1+(Z / 6.9)}\right.}
\end{gathered}
$$

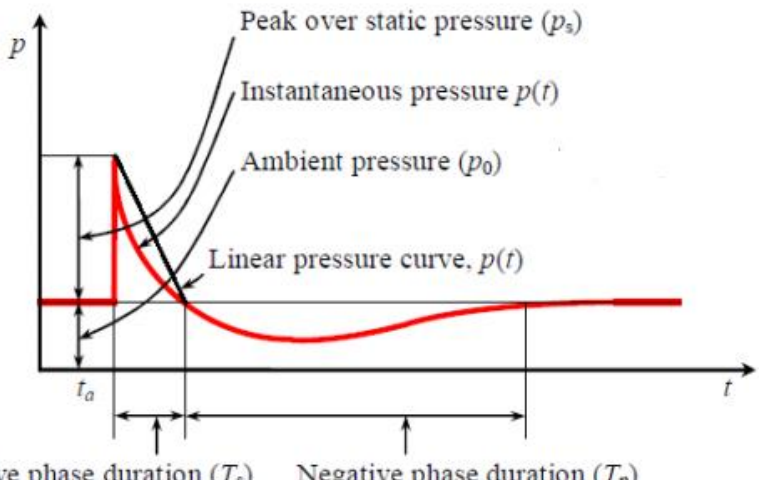


Fig. 1 The exponential blast wave decaying pressure-time history

Figure 2 shows the distribution of the pressure on the ground surface due to the blast load.

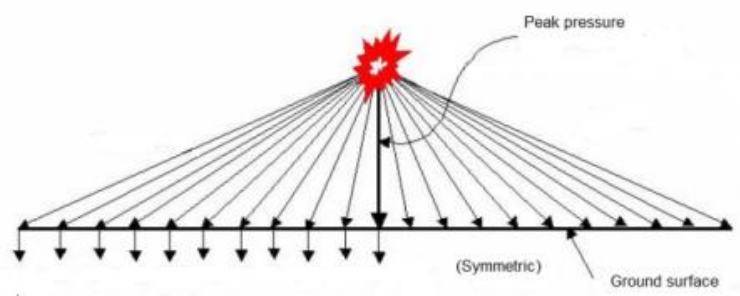

Fig. 2 Pressure distribution on the ground surface.

When the explosive charge detonates with un yielding surface, the shock wave in theory has a hemispherical wave front and not the spherical wave front of an explosion in free air. The energy of the explosion is therefore concentrated over a smaller total surface area, and theoretically all the previous relationships for free-air burst will still be valid if twice of the charge weight $(2 W)$ is substituted for $W$ in the equations. However, for a yielding surface, like the ground surface, which is capable of absorbing part of the energy (as in case crater formation), the factor of the charge weight is reduced to 1.7 [6]. These equations have been used in the present analysis.

\section{FINITE ELEMENT MODEL}

A typical barrage was used in this research. This barrage consists of 7 concrete piers and 2 abutments at its sides carrying a slab bridge. The piers and the abutments are rested on reinforced concrete raft foundation. The breadth and the height of each pier are $2 \mathrm{~m}$, and $6 \mathrm{~m}$, respectively. The breadth of the abutment is $3 \mathrm{~m}$. The spacing between the centerline of the piers is $7 \mathrm{~m}$. The thickness of the raft foundation is $1.5 \mathrm{~m}$. The water level is considered at $0.5 \mathrm{~m}$ under the top of the piers. The concentrated vertical load on the pier and on the abutment was taken as $250 \mathrm{KN}$, and $125 \mathrm{KN}$, respectively. Young's modulus, Poisson's ratio, and density of the concrete were taken as $2.1 \times 10^{7} \mathrm{KN} / \mathrm{m}^{2}, 0.2$, and $20 \mathrm{KN} / \mathrm{m}^{3}$, respectively.

Non-linear Finite element dynamic analysis was carried out using Plaxis software package [7]. The piers and the abutments of the barrage were modeled using plate elements. The loads of the bridge were implemented in the model as concentrated loads. The surrounding soil was modeled using plane strain elements with 15 nodes and Mohr-Coulomb soil model were used to model the soil. Tension cut off was used to prevent the tensile stress which is not allowed in the soil element during the analysis. The soil properties were chosen to model relatively stiff soil. The modulus of elasticity, angle of internal friction, Poisson's ratio, cohesion, and density of the soil were taken as $15,000 \mathrm{KN} / \mathrm{m}^{2}, 30^{\circ}, 0.22,60$, and $19 \mathrm{KN} / \mathrm{m}^{3}$, respectively. 
The height of soil above the bed rock in the finite element mesh was assumed to be $40 \mathrm{~m}$. In order to avoid the reflection of the waves from side boundaries into the model, absorbent boundaries were used and the sides of the model were chosen relatively far from the region of interest, (so that the width of the Finite Element mesh was taken $=360 \mathrm{~m})$. Interface elements were used to model the soil structure interaction between the soil and the plate elements. The blast load was implemented in the model using a time history distributed load with peak pressure $\left(\mathrm{P}_{\mathrm{s}}\right)=22000$ $\mathrm{KN} / \mathrm{m}^{2}$ with $1 \mathrm{~m}$ length, and the positive phase duration $\mathrm{T}_{\mathrm{s}}=0.9$ seconds. This load is equivalent to a charge weight $=100 \mathrm{Kg}$ of TNT exploded at a distance $=0.5 \mathrm{~m}$ from the ground surface. The spacing between the blast load and the abutment of the barrage was assumed $=20 \mathrm{~m}$. Figure 3 shows a part of the Finite element model of the barrage and the surrounding soil.

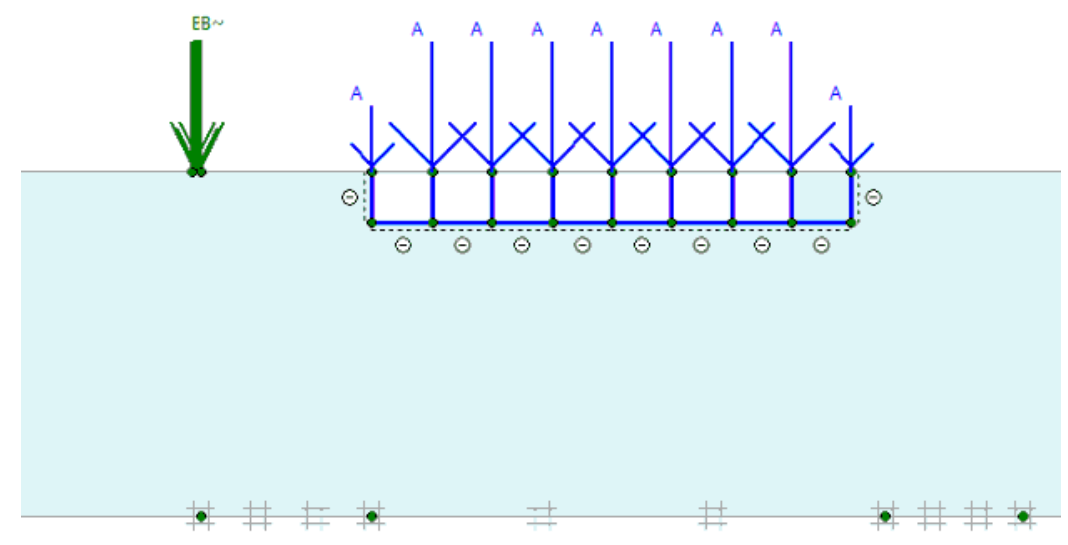

Fig.3 Part of the Finite Element model for the barrage.

\section{USING OPEN TRENCH AS A LOW-COST WAVE BARRIER}

An open trench is used in the analysis as a low cost wave barrier to reduce the effect of the blast load on the structural elements of the barrage. The structure responses due to the blast load obtained from the dynamic analysis of the FE model with and without the trench were compared directly in the time domain to investigate the effect of the trench on the internal forces induced in the barrage during blasting.

A trench barrier of width $\mathrm{W}$ and depth $\mathrm{D}$ is assumed to be 1 ocated at a distance $\mathrm{L}$ measured from the centerline of the trench to the left abutment. The trench width $\mathrm{W}$, the depth $\mathrm{D}$ and the distance $\mathrm{L}$ are assumed to be variable parameters. $\mathrm{D}$ was taken as $4 \mathrm{~m}, 6 \mathrm{~m}, 8 \mathrm{~m}$, and $10 \mathrm{~m}$ (which corresponding to about $67 \%, 100 \%, 133 \%$, and $167 \%$ of the barrage depth considered in the Finite Element model). W was taken as $0.5 \mathrm{~m}$, $1 \mathrm{~m}$, and $1.5 \mathrm{~m}$. L was taken as $3 \mathrm{~m}, 6 \mathrm{~m}, 10 \mathrm{~m}$, and $14 \mathrm{~m}$. The configuration of the open trench is shown in Fig. 4.

Therefore, unless otherwise specified, the depth D of the trench, its width W, and the distance $\mathrm{L}$ were taken as $8 \mathrm{~m}, 1.0 \mathrm{~m}$, and $10 \mathrm{~m}$, respectively. 


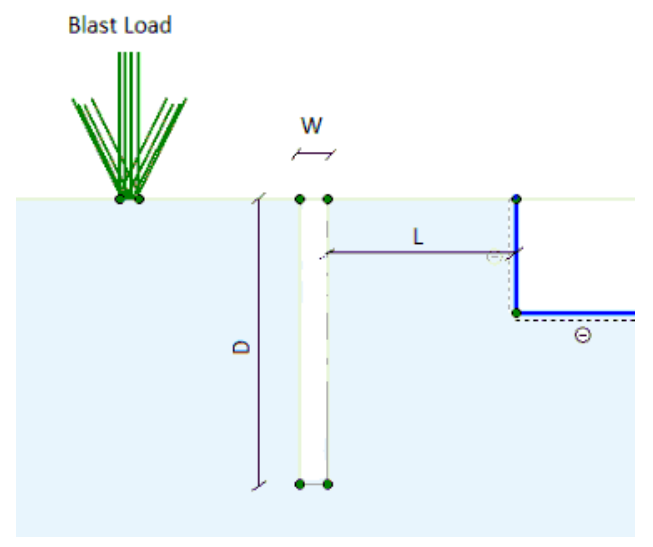

Fig. 4 Configuration of the open trench

Noting that in stiff soil such as; sandy silt to salty clay, or in rock, the excavated trench may stay stable (depends on soil properties) without collapse and for some other types of soil there is a need to support the trench sides .

The responses of the structure obtained from the non -linear dynamic analysis were obtained for the model with and without trench. The percentages of the reduction in the maximum moment due to the existence of the open trench were calculated. The maximum moment due to the blast load occurred at the intersection between the left abutment and the foundation (the lower left corner of the structure). The results are presented in the following sections.

\section{EFFECT OF TRENCH DEPTH}

The effect of trench depth on the internal forces, velocity, and displacements of the structure were calculated due to the blast load.

\subsection{Effect of Trench Depth on the Internal Forces}

Figure 5 shows the relation between the percentage of the reduction in the maximum moment and the trench depth. As shown in this figure, the reduction in the moment increases with the increase of the trench depth. This reductio $n$ was $3.56 \%, 22.41 \%$, $51.38 \%$, and $61.02 \%$ when the trench depth was $4 \mathrm{~m}, 6 \mathrm{~m}, 8 \mathrm{~m}$, and $10 \mathrm{~m}$, respectively. This means that the trench depth has significant effect on the percentage of the reduction in the maximum moment. 


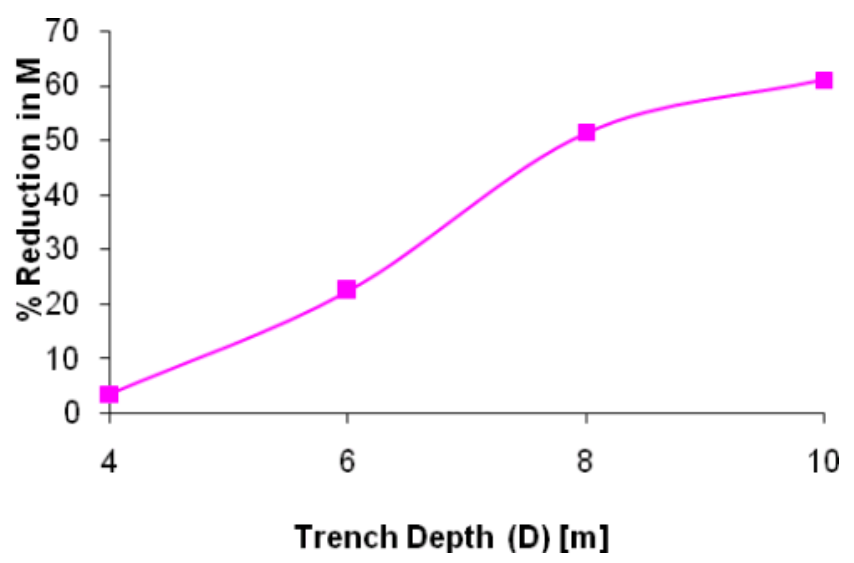

Fig. 5 Relation between trench depth and \% reduction in the Max. M.

\subsection{Effect of Trench Depth on the Velocity and Displacement}

Many specifications specify the velocity of the particles during the blast as the criteria used to assess the damage in the structure. The following sections describe the variation of velocity and the displacement with time during the blast load (at the location of the maximum moment) in the vertical and in the horizontal direction,

respectively, for the cases of; no trench, and existence of trench with depth $=8 \mathrm{~m}$, and $10 \mathrm{~m}$. Comparisons of the results were carried out using the maximum values of the displacement and velocity in each case.

\subsubsection{Effect of trench depth on the velocity}

Figure 6 shows the velocity time history in the vertical and horizontal direction s. As shown in this figure, the maximum vertical velocity occurred in the case of no trench was $1.08 \mathrm{~m} / \mathrm{s}$ while the maximum vertical velocity occurred in the case of trench depth $=10 \mathrm{~m}$, was $0.62 \mathrm{~m} / \mathrm{s}$.

The maximum horizontal velocity occurred in the case of no trench was $0.94 \mathrm{~m} / \mathrm{s}$, while the maximum horizontal displacement occurred in the case of trench depth $=$ $10 \mathrm{~m}$ was $0.56 \mathrm{~m} / \mathrm{s}$. 


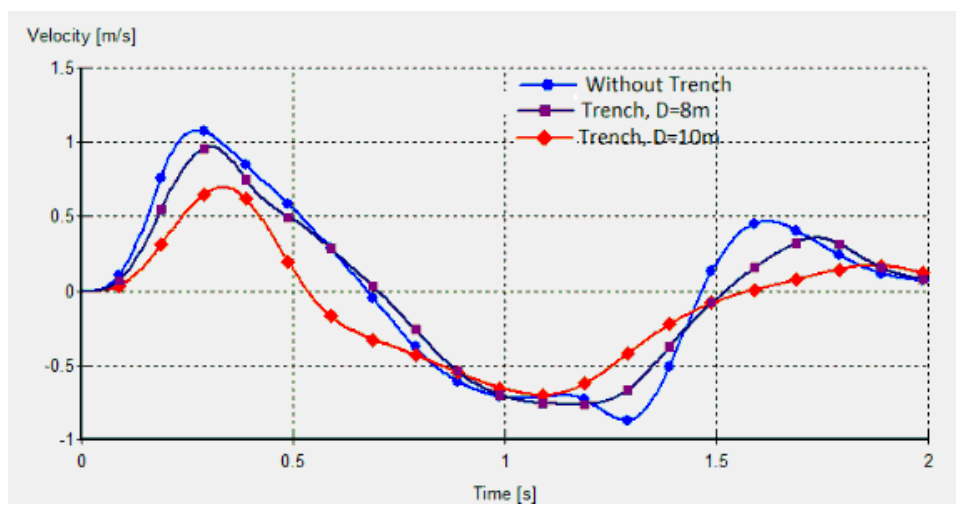

(a)Velocity time history in Vl. dir.

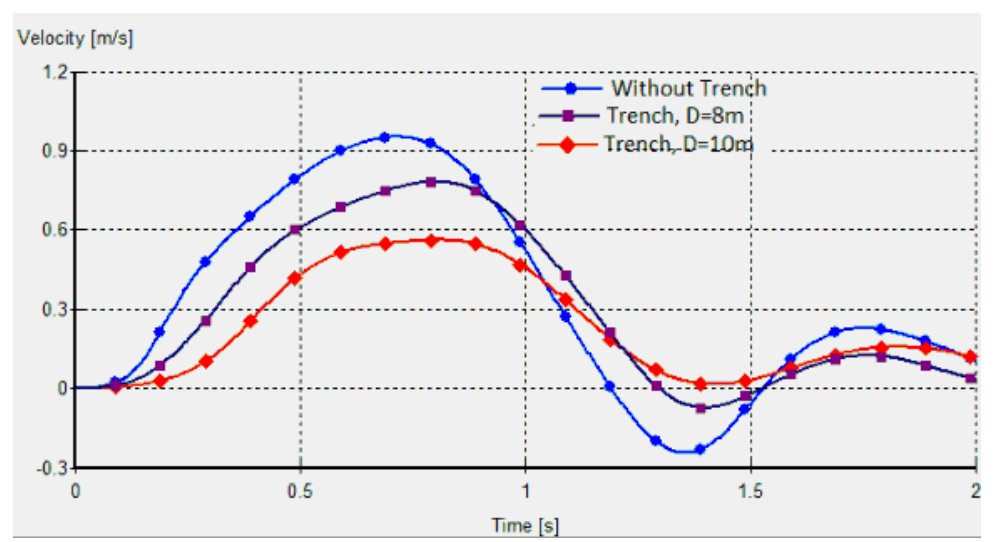

(b) Velocity time history in Hl. dir.

Fig. 6 Velocity time history in V1. and Hl. directions.

The percentage of reduction in the velocity due to the existence of trench with $10 \mathrm{~m}$ depth, in the vertical and in the horizontal directions was $42.6 \%$, and $40.4 \%$, respectively.

\subsubsection{Effect of trench depth on the displacement}

Figure 7 show the displacement time history in the vertical and horizontal directions. As shown in this figure, the maximum vertical displacement occurred in the case of no trench was $0.37 \mathrm{~m}$, while the maximum horizontal displacement occurred in the case of trench depth $=10 \mathrm{~m}$ was about $0.18 \mathrm{~m}$.

The maximum horizontal displacement occurred in the case of no trench was $0.68 \mathrm{~m}$, while the maximum horizontal displacement occurred in the case of trench depth $=$ $10 \mathrm{~m}$ was $0.46 \mathrm{~m}$. 


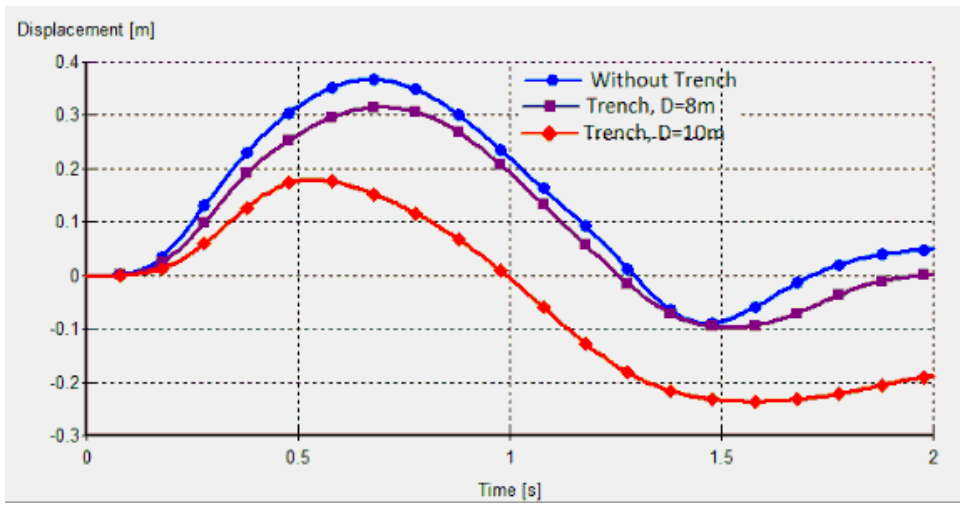

(b) Displacement time history in Vl. dir.

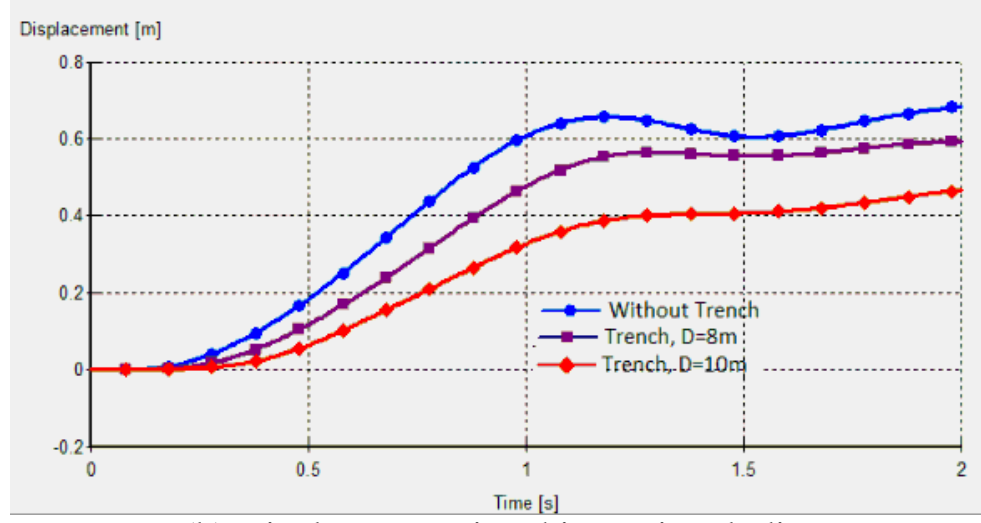

(b) Displacement time history in Hl. dir.

Fig. 7 Displacement time history in Vl. and Hl. directions.

The percentage of reduction in the displacement in the vertical and in the horizontal directions was $32.4 \%$, and $51.4 \%$, respectively.

Figure 6, and Fig. 7 show that the maximum velocity occurred in the vertical direction while the maximum displacement occurred in the hor izontal displacement.

\subsection{Effect of Trench Location}

Figure 8 shows the relation between the percentage of the reduction in the maximum moment and the distance from the left abutment to the trench. As shown in this figure, the reduction in the moment decreases with the increase of the trench distance This reduction was $59.34 \%, 57.24 \%, 51.38 \%$, and $42.3 \%$ when this distance was $3 \mathrm{~m}, 6 \mathrm{~m}$, $10 \mathrm{~m}$, and $14 \mathrm{~m}$, respectively. This means that when the trench is located near the structure, the efficiency of the trench to reduce the internal forces due to blast increases. 


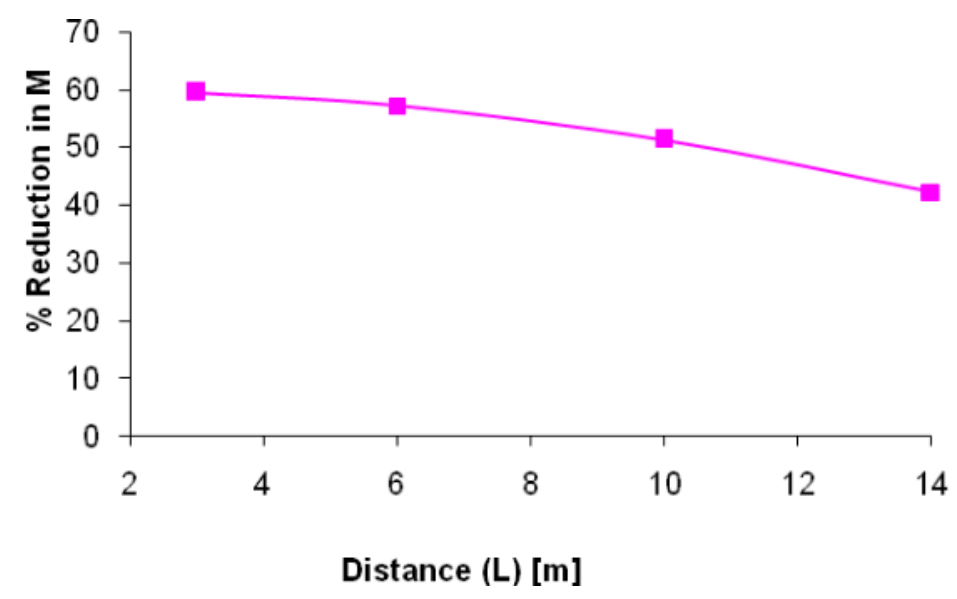

Fig. 8 Relation between distance (L) and \% reduction in the Max. M.

\subsection{Effect of Trench Width}

Figure 9 shows the relation between the percentage of the reduction in the maximum moment and the trench width when the trench depth was $6 \mathrm{~m}$ and $8 \mathrm{~m}$. As shown in this figure, when the trench width increases the percentage of the reduction is approximately the same. This means that this increase in the trench width (from $0.5 \mathrm{~m}$ to $1.5 \mathrm{~m}$ ), has no or very little effect on the percentage of the reduction in the maximum moment.

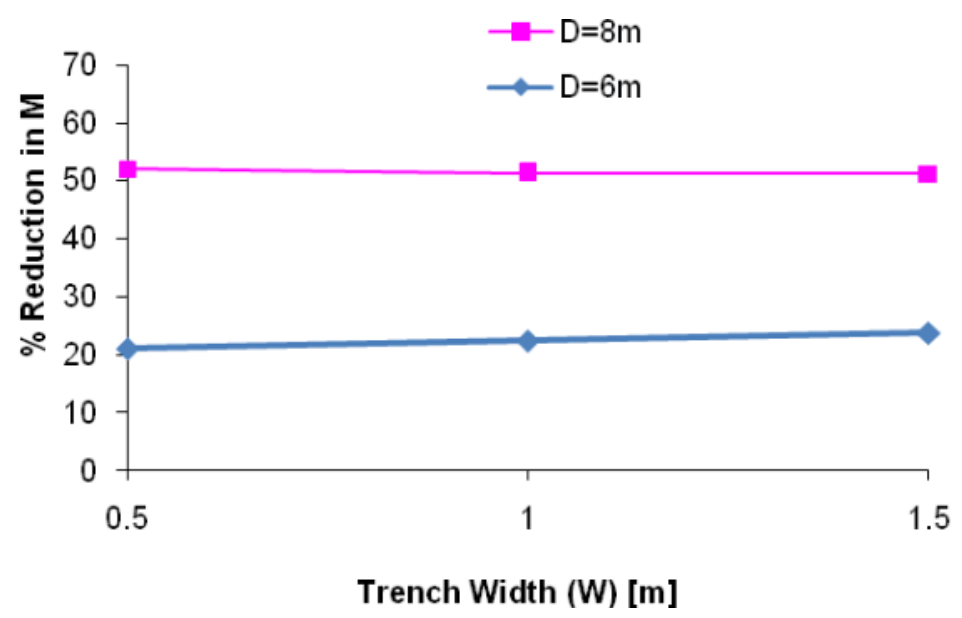

Fig. 9 Relation between trench width and \% reduction in the Max. M.

\section{CONCLUSIONS}


The effectiveness of using open trench as a low -cost barrier to reduce the internal forced induced in the structure during the blast was investigated and the following conclusions may be drawn:

- Using open trench barriers can reduce the vib rations of the structure and the resulting internal forces significantly (a reduction level up to 61\%) of the internal forces and a reduction in the velocity and displacement could be observed.

- The trench depth has a significant effect on the percentage of the reduction in the maximum moment. The reduction in the moment increases with the increase of the trench depth

- When the trench is located near the structure, the efficiency of the trench on reducing the internal forces due to blast increases.

- The increase in the trench width (from $0.5 \mathrm{~m}$ to $1.5 \mathrm{~m}$ ), has no or very little effect on the percentage of the reduction in the maximum moment.

- The maximum velocity occurred in the vertical direction while the maximum displacement occurred in the horizontal displaceme nt due to the blast load.

\section{REFERENCES}

1- Huabei Liu, "Dynamic Analysis of Subway Structures under Blast Loading", Final Report - Department of Civil Engineering, the City College of New York sponsored by University Transportation Research Center, US A, 2009.

2- Kumar,M., Matsagar, V., and Rao, K., " Blast Loading on Semi-Buried Structures with Soil-Structure Interaction, "Proceedings of the IMPLAST 2010 Conference, Society for Experimental Mechanics, Rhode Island, USA.

3- Nagy, N., Mohamed, M. and Boot, J., "Nonlinear Numerical Modelling for the Effects of Surface Explosions on Buried Reinforced Concrete Structures", Geomechanics and Engineering Journal, Vol. 2, No. 1, pp. 1-18, 2010.

4- Alzawi A., and Naggar, M., " Full scale experimental study on vibration scattering using open and in-filled (GeoFoam) wave barriers", Soil Dynamics and Earthquake Engineering Journal Vol. 31 pp. 306-317, 2011.

5- Adam, M., and Estorff, V., "Reduction of train-induced building vibrations by using open and filled trenches", Computers and Structures Journal, Vol. 83, pp. 1124, 2005.

6- Bulson, P.S. "Explosive loading of engineering structures", Chapman and Hall, U.K., 1997.

7- Plaxis Professional Ver. 8, "Dynamic Manual", Delft University of Technology and Plaxis b. v., The Netherlands, 2002. 